\title{
Signo ecográfico de las capas de cebolla en el testículo
}

\section{Onion Ring Sign in the Testicle}

\author{
Guillermo Aguilera ${ }^{1}$ Velimir Skoknic ${ }^{1}$ Mario Mora ${ }^{2}$ \\ 1 Universidad del Desarrollo, Concepción, Región del Bío Bío, Chile \\ ${ }^{2}$ Clínica Alemana de Santiago, Vitacura, Región Metropolitana, Chile \\ Address for correspondence Guillermo Esteban Aguilera, MD, \\ Universidad del Desarrollo, Concepción, Región del Bío Bío, Chile \\ (e-mail: gaguileras@alemana.cl).
} Rev Argent Radiol 2019;83:180-182.

\begin{abstract}
Resumen
Palabras clave

- ultrasonido

- quiste epidermoide testicular

Los quistes epidermoides del testículo son tumores benignos que representarían aproximadamente el $1 \%$ de todas las masas testiculares. Clínicamente es una patología poco sintomática, que se presenta como un aumento de volumen testicular o es detectado en exámenes de rutina. La ecografía demuestra una lesión focal del testículo, ovalada, heterogénea, con múltiples capas lineales hiperecogénicas concéntricas que da el signo clásico de "capas de cebolla" o con morfología de "anillo", y que no presenta flujo al Doppler color (-Figuras 1-3). Cabe señalar también que se ha descrito la presencia de calcificaciones murales o una imagen hiperecogenica central como forma de presentación. Es necesario tener en cuenta que existen algunas publicaciones que describen casos aislados en que esta apariencia ecográfica característica podría también estar presente en teratomas, el cual sería su principal diagnóstico diferencial. La importancia del conocimiento de esa lesión radica en la alta probabilidad de ser una lesión benigna, que puede ser tratada con enucleación y no necesariamente requerir orquiectomia extendida, ya que hasta ahora, no existen reportes de malignización, diseminación ni recurrencia.
\end{abstract}

\section{Introducción}

El signo ecográfico de las capas de cebolla en una lesión testicular consiste en la presencia de una imagen ovalada o redonda, de bordes bien delimitados, que presenta múltiples imágenes lineales hiperecogénicas de distribución concéntrica. Eso determina un aspecto similar al interior de una cebolla. Si bien ella no es la presentación más frecuente, es bastante específica de los quistes epidermoides. ${ }^{1}$

Los quistes epidermoides del testículo son tumores benignos, que representan aproximadamente entre el $1 \%$ y el $2 \%$ de todas las masas testiculares. ${ }^{2}$ Se atribuye su primera descripción a Dockerty y Priestley ${ }^{3}$ en el año 1942, quienes publicaron tres casos de entre 400 biopsias. Sin embargo, el primer reporte en ultrasonido (US) a esa descripción anatomopatológica se logró después de 40 años. ${ }^{2}$ Posteriormente, se han ido agregando sus características imagenológicas en esa modalidad y en resonancia magnética (RM), principalmente a través de reportes de casos clínicos, debido a su baja frecuencia. Clínicamente, es una patología poco sintomática, que se presenta como un aumento de volumen testicular indoloro o es detectado en exámenes de rutina como una masa indurada, con ausencia de elevación de marcadores tumorales (alfa-fetoproteína (AFP), lactato-deshidrogenasa (LDH) y beta-gonadotropina coriónica humana (bHCG)). Generalmente, afecta a hombres entre la segunda y la cuarta década de la vida, predominando en la raza blanca y en el testículo derecho. Su tamaño varía de 1 a $3 \mathrm{~cm} .^{2}$

En US su característica más frecuente es la presencia calcificaciones murales. También se ha descrito, en menos casos, como una lesión ovalada de centro hiperecogénico. ${ }^{1}$ Pero, como ya se ha mencionado previamente, la descripción clásica corresponde a una lesión ovalada o redondeada, bien delimitada, con múltiples imágenes lineales hiperecogénicas received

June 24, 2018

accepted

May 15, 2019
DOI https://doi.org/

$10.1055 / \mathrm{s}-0039-1692438$.

ISSN 1852-9992.
Copyright @ 2019, Sociedad Argentina de Radiología. Publicado por Thieme Revinter Publicações Ltda., Rio de Janeiro, Brazil. Todos los derechos reservados.

\section{License terms}

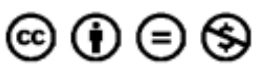




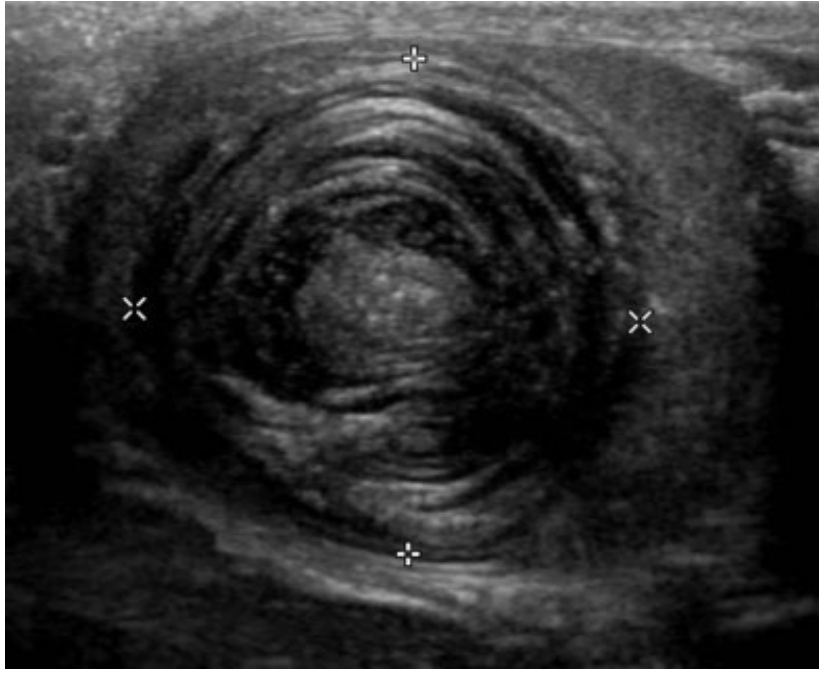

Fig. 1 Ecografía testicular, corte transversal del testículo izquierdo. Hombre de 37 años sin antecedentes mórbidos, que consulta por disuria, constatándose en el examen físico una masa indurada en el polo superior del testículo izquierdo, no dolorosa. Exámenes de laboratorio hemograma, orina, AFP, LDH y bHCG dentro de los límites normales. La ecografía demuestra una lesión focal en el polo superior del testículo izquierdo de $23 \times 19 \mathrm{~mm}$, ovalada, heterogénea con múltiples capas lineales hiperecogénicas concéntricas.

de disposición concéntrica (-Figs. 1-3). Es importante destacar que, de todas sus formas de presentación, ninguna de ellas exhibe vascularización al modo Doppler color. Esas características son extrapolables a la RM, donde se observa una cápsula de baja intensidad y capas internas concéntricas de alta señal ponderadas en T1 y T2. ${ }^{2}$ Todos esos hallazgos se relacionan con la anatomía patológica, que en la pieza macroscópica se observa como una masa blanquecinagrisácea bien delimitada ( - Fig. 4), mientras que en la histología se compone de tejido fibroso periférico rodeando una lesión quística con capas de epitelio escamoso estratificado queratinizado. Sin embargo, es necesario tener en cuenta que existen algunas publicaciones que describen casos aislados en que esa apariencia ecográfica podría también

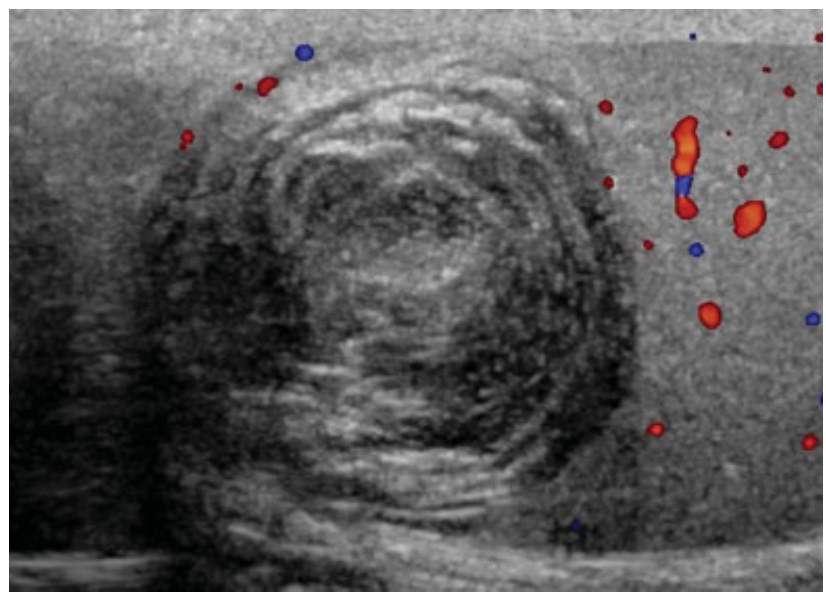

Fig. 2 Ecografía testicular con modo Doppler color, corte transversal del testículo izquierdo. Se observa la ausencia de flujo al modo Doppler color de la lesión previamente descrita.

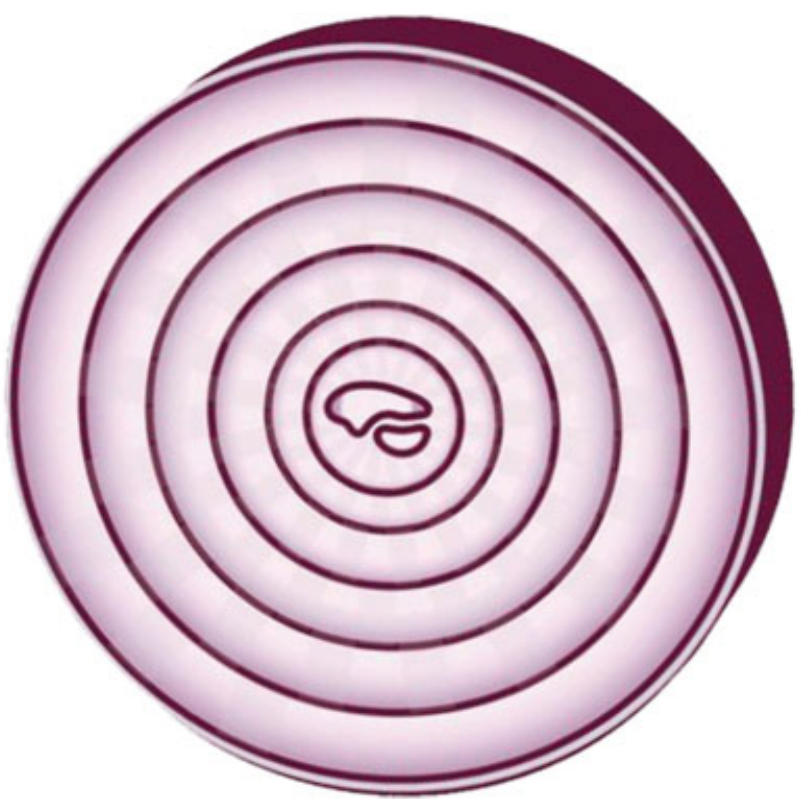

Fig. 3 Esquema del interior de una cebolla. Similitud de las imágenes lineales hiperercogénicas concéntricas a la imagen habitual del signo de las capas de cebolla.

estar presente en teratomas, lo cual es un importante diagnóstico diferencial a tener en cuenta. ${ }^{4}$

La presencia de una clínica mayoritariamente asintomática, la imagen en capas de cebolla y la ausencia

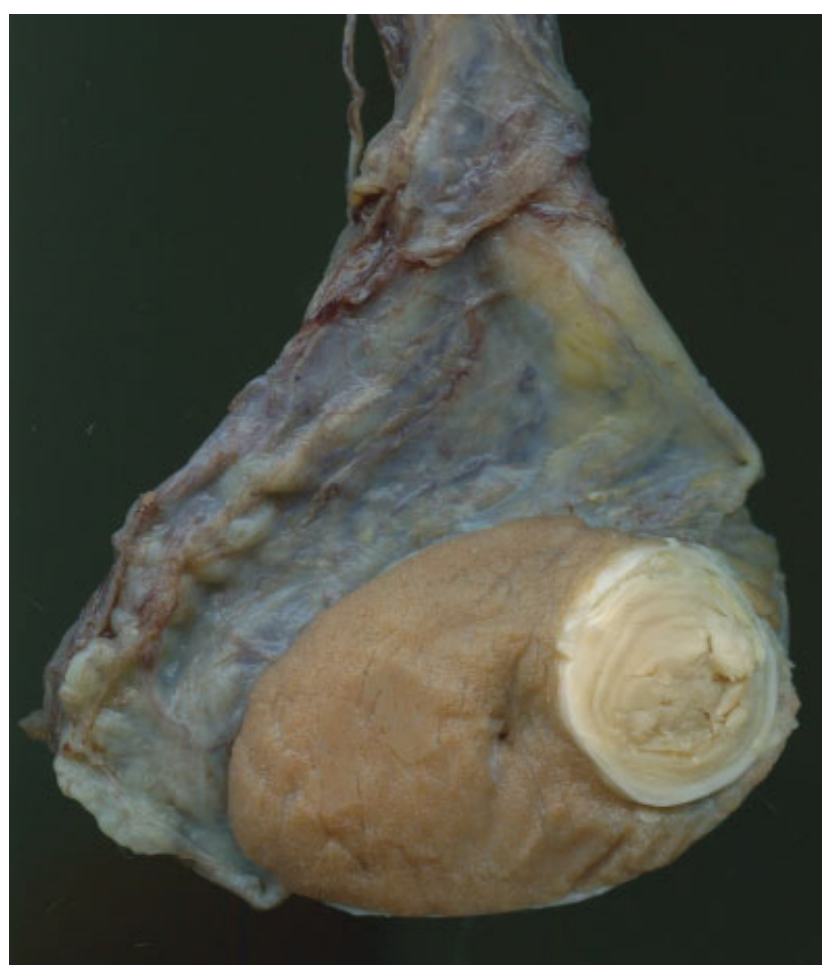

Fig. 4 Pieza macroscópica de anatomía patológica. Se observa la lesión blanquecina ovalada, bien delimitada, del polo superior del testículo izquierdo. 
de marcadores tumorales sanguíneos, permiten realizar un diagnóstico certero de un quiste epidermoide. ${ }^{1}$

La importancia del conocimiento de esa forma de presentación característica radica en que, sugerido el diagnóstico, permite realizar un tratamiento con enucleación, respetando el resto del parénquima testicular, y así evitar realizar una orquiectomía extendida. Hasta ahora, no existen reportes de malignización, diseminación ni recurrencia. $^{5}$

\section{Conclusión}

El signo de las capas de cebolla es una imagen altamente sugerente de una patología poco frecuente como los quistes epidermoides intratesticulares, su identificación tiene una gran importancia en el manejo posterior de los pacientes, ya que permite al clínico realizar un abordaje más conservador en la cirugía.
Conflicto de intereses

Los autores declaran no tener ningún conflicto de intereses.

\section{Bibliografía}

1 Manning MA, Woodward PJ. Testicular epidermoid cysts: sonographic features with clinicopathologic correlation. J Ultrasound Med 2010;29(05):831-837

2 Cho JH, Chang JC, Park BH, Lee JG, Son CH. Sonographic and MR imaging findings of testicular epidermoid cysts. AJR Am J Roentgenol 2002;178(03):743-748

3 Dockerty MD, Priestly JY. Dermoid cysts of the testis. J Urol 1942; 48:392-397

4 Maizlin ZV, Belenky A, Baniel J, Gottlieb P, Sandbank J, Strauss S, Epidermoid cyst and teratoma of the testis: sonographic and histologic similarities. J Ultrasound Med 2005;24(10): 1403-1409, quiz 1410-1411

5 Ashouri KB, Heiman JM, Kelly EF, Manganiotis AN. Testicular epidermoid cyst: A rare case. Urol Ann 2017;9(03):296-298 